\title{
Strong and machinable carbon aerogel monoliths with low thermal conductivity prepared via ambient pressure drying
}

Xianfeng Jia ${ }^{\text {a }}$ Bowen Dai ${ }^{\text {a }}$,Zhaoxian Zhu ${ }^{\text {a }}$, Jitong Wang ${ }^{\text {a }}$,Wenming Qiao ${ }^{\text {a b }}$, Donghui Long* a, b, Licheng Ling a, b

${ }^{a}$ State Key Laboratory of Chemical Engineering, East China University of Science and Technology, Shanghai 200237, China

${ }^{\mathrm{b}}$ Key Laboratory of Specially Functional Polymeric Materials and Related Technology, East China University of Science and Technology, Shanghai 200237, China.

* Corresponding author:

Tel: +8621 64252924. Fax: +862164252914.

E-mail: longdh@mail.ecust.edu.cn. (Donghui Long) 


\section{Abstract}

Carbon aerogels are among the most attractive porous carbon materials currently, but their real-world applications are greatly limited by their high cost, complicated preparation process and low mechanical properties. Herein, we report a very facile route to prepare lightweight but mechanically strong carbon aerogel monoliths (CAMs), through a sol-gel polymerization of linear phenolic resin and hexamethylenetetramine (HMTA), followed by ambient pressure drying and carbonization. The good capability of linear phenolic resin with ethanol could induce the formation of large polymer particle and good particle connectivity, affording robust network to suppress the collapse during the ambient drying. The synthesis is scalable and flexible, permitting a facile tailor of density, porous structure and mechanical strength by adjusting the ratio of phenolic resin to HMTA and phenolic resin concentration. The obtained CAMs possess macroporous/microporous hierarchical structure with low density as low as $0.07 \mathrm{~g} \mathrm{~cm}^{-3}$, high mechanical strength of $0.9-5.0 \mathrm{MPa}$ and low thermal conductivity (0.032-0.069 $\left.\mathrm{W} \mathrm{m}^{-1} \mathrm{~K}^{-1}\right)$. Further $\mathrm{CO}_{2}$ activation can greatly develop the microporosity without sacrificing the monolithic structure. Moreover, as-prepared CAMs can be fabricated in large sizes, as well as being post-machined into many shapes and sizes for potential applications. 


\section{Introduction}

Carbon aerogels are one of the most promising new carbon forms with 3-D network structures consisting of interconnected carbon particles [1-5]. These materials exhibit many fascinating physiochemical properties, including continuous porosity, large surface area and excellent conductivity, making them possess many promising applications, such as thermal and phonic insulators $[6,7]$, catalyst supports $[8,9]$, adsorbents $[10,11]$ and electrodes for supercapacitors $[12,13]$. Generally, carbon aerogels are prepared via high-temperature pyrolysis of organic aerogels, which are synthesized through the sol-gel polymerization of resorcinol and formaldehyde (RF) in aqueous solutions [14-16]. The key issue in the preparation of organic and carbon aerogels is how to remove the solvents from the wet gels while maintaining the integrity and high porosity of the gels. This thus need supercritical extraction of the solvents, which possess high solvating power and almost zero surface tension preventing the network collapse that is induced by capillary forces [3]. However, supercritical processing is highly dangerous, costly and incompatible with the processing required for many potential applications, severely limiting the commercial exploitation of organic and carbon aerogels. Consequently, ambient pressure drying has drawn considerable research attention and should be a critical development for low-cost preparation of carbon aerogels $[17,18]$.

Many efforts have been directed toward the development of organic and carbon aerogels production with ambient pressure drying [20-25]. It is believed that an appropriate network strength, together with large particle size/macroporous network and low surface tension, is 
significant in reducing collapse and shrinkage of pore structure during ambient pressure drying [19]. Fricke et al. [20] described a synthesis route for RF aerogels using ambient pressure drying for the first time. They observed that the combination of high resorcinol-to-catalyst molar ratio (e.g. 1000-1500) with high reaction concentration could lead to gels with sufficient network strength, which can withstand the high capillary forces during ambient pressure drying. But the resulting carbon aerogels have a fairly high bulk density in the range of 0.35 to $1.0 \mathrm{~g} \mathrm{~cm}^{-3}$. Wu et al [21] fabricated the mesoporous carbon aerogels by the addition of cetyltrimethyl ammonium bromide, which could decrease surface tension of gels, thus minimizing pore collapse during the ambient pressure drying. Still, the obtained carbon aerogels held a high density of more than $0.4 \mathrm{~g} \mathrm{~cm}^{-3}$. Ratke et al [22] employed highly concentrated $\mathrm{HCl}$ as catalysts for resorcinol-formaldehyde mixture, which can form nearly spherically shaped micrometer-sized particles and resulting particle-overlapped macroporous structure. Unfortunately, the obtained aerogel has very poor mechanical properties. On the other hand, some investigations have been undertaken to strengthen gel skeletons by reinforcing with carbon cloth [23], carbon fibers [24, 25] or ceramic fiber [26]. Unfortunately, these approaches not only increase the bulk density but also lead to the formation of large cracks during the pyrolysis. So far, it is still a very challenging task to prepare low-density carbon aerogels with integrity structure by ambient pressure drying.

Monolithicity is one of important features of carbon aerogels required for many potential applications like thermal insulation, binding-free electrodes [27]. However, their intrinsically fragility and brittleness severely complicate handling or processing without catastrophic 
fracture of the materials. Hence, improving the mechanical properties of carbon aerogel monoliths is an important fundamental challenge towards achieving the full potential of these materials [28, 29]. Unfortunately, the high mechanical properties always conflict with low density and high porosity of the materials. How to balance the strength and low density of carbon aerogels presents a challenge, especially for these prepared by the ambient pressure drying. Once the production costs are substantially reduced and their mechanical properties improved, carbon aerogels should stand up to real-world applications [30].

Herein, we report a facile and low-cost route to prepare low-density but mechanically robust carbon aerogel monoliths (CAMs) through the ambient pressure drying. The key to the synthesis is employing commercial available linear phenolic resin as precursor and hexamethylenetetramine (HMTA) as a cross-linking reagent in alcohol solutions. The obtained CAMs possess hierarchical structure containing micropores within the individual particle, and macropores in the interstitial voids between them. Moreover, as-prepared robust CAMs have low density and low thermal conductivity, which can be fabricated in large sizes, as well as being post-machined into many shapes and sizes for various applications. The developed method is a green chemistry process that avoids the expensive starting materials and troublesome steps, e.g. solvent exchange nor supercritical drying of the current technologies. These superior monolithic carbon aerogels may well be the answer to a low cost-high performance compromise in high-temperature insulators, electrode materials, adsorbents and catalyst supports.

\section{Experimental}

\subsection{Materials Preparation}


Organic aerogel monoliths (OAMs) were synthesized via a sol-gel polymerization of linear phenolic resin and hexamethylenetetramine (HMTA) in alcoholic solutions. Typically, 5-50 g linear phenolic resin $(\mathrm{P})$ were mixed with HMTA $(\mathrm{H})$ in $100 \mathrm{ml}$ ethanol, and the weight ratios of $\mathrm{P}$ and $\mathrm{H}(\mathrm{P} / \mathrm{H})$ were varied from 3 to 10 . After completely dissolved, the resultant solutions were transferred into plastic vials. The vials were sealed and placed into water bath at $80{ }^{\circ} \mathrm{C}$ for gelation/aging to form alcogels. Typically, the gel time is about $8-16 \mathrm{~h}$, and the aging time is 3 days. The obtained alcogel monoliths were directly dried in air at room temperature for 1 day, and finally dried in an oven at $80^{\circ} \mathrm{C}$ for 1 day to obtain OAMs. Carbon aerogel monoliths (CAMs) were obtained by pyrolysis of OAMs at $900{ }^{\circ} \mathrm{C}$ for $2 \mathrm{~h}$ with the heating rate of $3{ }^{\circ} \mathrm{C} \min ^{-1}$ under nitrogen atmosphere. These organic and carbon aerogel monoliths are denoted as OAM-x-y and CAM-x-y, respectively, where $\mathrm{x}$ represents the concentration of linear phenolic resin and y refers to the ratio of $\mathrm{P} / \mathrm{H}$.

The $\mathrm{CO}_{2}$ activation was performed in a ceramic tube furnace under flowing nitrogen with a heating rate of $10{ }^{\circ} \mathrm{C} \min ^{-1}$ up to $950{ }^{\circ} \mathrm{C}$. After reaching this temperature, the activating gas $\mathrm{CO}_{2}$ was introduced for $2 \mathrm{~h}$ and then switched back to nitrogen to prevent further activation during the cooling process. The activated carbon aerogel monoliths were denoted as CAM-X-5- $\mathrm{CO}_{2}$.

\subsection{Characterization}

The volume shrinkage of OAMs was calculated by measuring the dimensions of each cylindrical sample before and after ambient pressure drying. The bulk densities $\rho$, volume shrinkage and carbonization yield of CAMs were determined by measuring the dimensions and mass of each cylindrical sample before and after carbonization process. 
The chemical structures of the linear phenolic resin and organic aerogel monoliths were investigated by solid-state ${ }^{13} \mathrm{C}-\mathrm{NMR}$ (Bruker AVANCE III $300 \mathrm{WB}$ spectrometer) and Fourier transform-infrared (Spectrum 100, PerkinElmer). The average molecular weight and polydispersity index (PDI) of the phenolic resin was measured by gel permeation chromatography (PL-GPC50, Polymer Laboratories).

The morphologies of the monoliths were observed under scanning electron microscopy (SEM, FEI-NOVA Nano SEM450) and transmission electron microscopy (TEM, JEOL 2100F).

Nitrogen adsorption/desorption isotherms were measured at $-196{ }^{\circ} \mathrm{C}$ with a Quadrasorb SI analyzer. Before the measurements, the samples were degassed in vacuum at $200{ }^{\circ} \mathrm{C}$ for 12 h. The Brunauer-Emmett-Teller (BET) method was utilized to calculate the specific surface areas $\left(S_{\mathrm{BET}}\right)$. The total pore volumes $\left(V_{\text {total }}\right)$ were estimated from the amount adsorbed at the maximal relative pressure of 0.995 . Micropore surface areas $\left(S_{\text {micro }}\right)$ and micropore volumes $\left(V_{\text {micro }}\right)$ were obtained via DFT method.

The macropore size distributions of the CAMs were determined by mercury porosimetry (PoreMaster33, Quantachrome). The mercury porosimetry measurement was performed between 0.01 and $20 \mathrm{MPa}$ after degassing the samples for $2 \mathrm{~h}$ at ambient temperature.

Compression tests were performed on cylindrical samples with the size of $\varphi 3 \times 5 \mathrm{~cm}$ using an Instron 3367 test with a compression rate of $2 \mathrm{~mm} \mathrm{~min}^{-1}$. The specimens were cut and polished to make sure that the top and bottom surfaces were smooth and parallel.

Thermal conductivity of the CAMs at $30{ }^{\circ} \mathrm{C}$ and $80{ }^{\circ} \mathrm{C}$ was measured by heat flux method (Netzsch, HFM436 Lambda). The sample dimensions for the thermal conductivity 
measurement were $10 \times 10 \times 1 \mathrm{~cm}$.

\section{Results and discussion}

\subsection{Preparation of OAMs and CAMs}

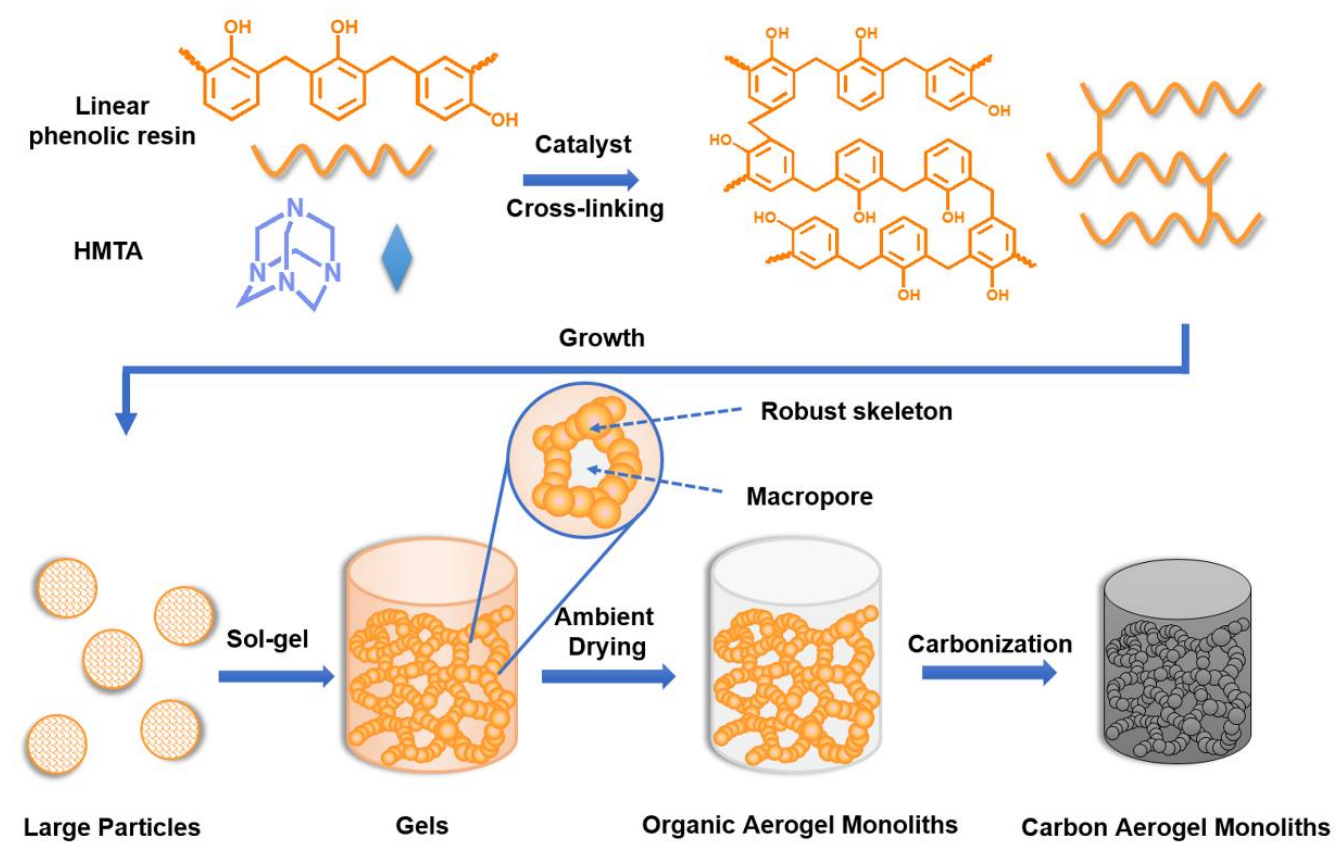

Fig. 1. Schematic illustration of the preparation of OAMs and CAMs.

As illustrated in Fig. 1, CAMs are prepared by a sol-gel process using linear phenolic resin and HMTA as precursors in ethanol solutions, followed by ambient pressure drying and carbonization. It has shown that two conflicting properties-low density and high mechanical strength could be simultaneously achieved in resultant monoliths. The key to the synthesis relies on thermoplastic linear phenolic resin as precursor, which could polymerize with hexamethylenetetramine (HMTA), and then cross-link to large colloid-like polymer clusters and robust gel network. The phenolic resin, synthesized by reacting excessive phenol with 
formaldehyde with an acid catalysis has linear structure with relatively high molecular weight $\left(M_{\mathrm{w}}=1500 \mathrm{~g} \mathrm{~mol}^{-1}\right.$, PDI $=1.13$, as measured by GPC in Fig. S1). Compared to the RF aqueous system, the present system has obvious advantages. The linear phenolic resin has lower steric hindrance and chain branching than 3-D branched RF oligomer. This will give a good compatibility of polymer with ethanol, leading to the formation of large-size colloidal clusters. Therefore, the obtained gels have macroporous cell size and robust network, which can withdraw the high capillary force during ambient pressure drying. Only slight volume shrinkages (typically between $8.7-11.2 \%$, see Table S1) of gels could be observed after the ambient pressure drying. The synthesis is a green chemistry process and very facile that employs low-cost starting materials and avoids the expensive steps e.g. solvent exchange nor supercritical drying. 
(a)

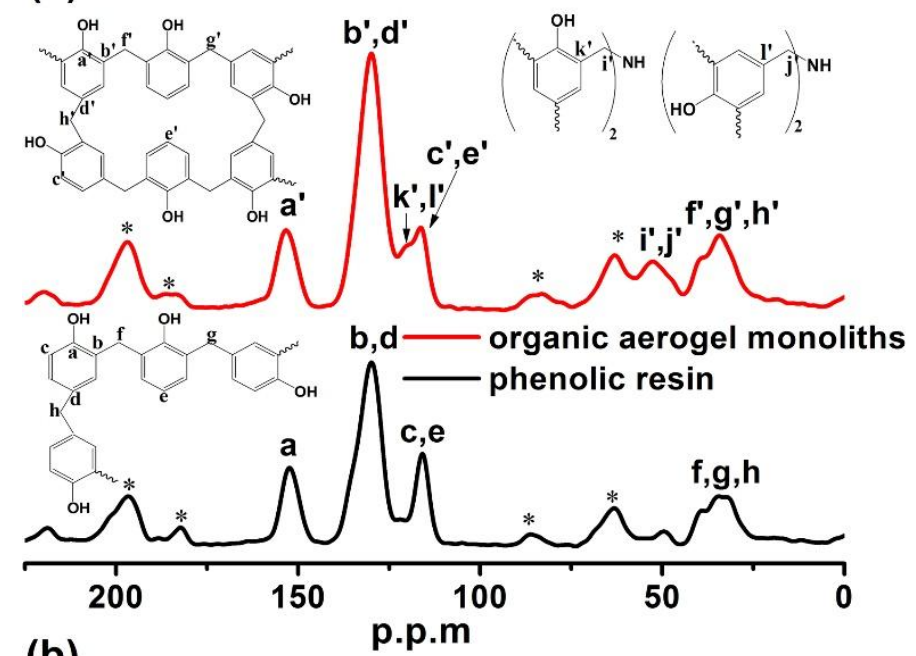

(b)

p.p.m

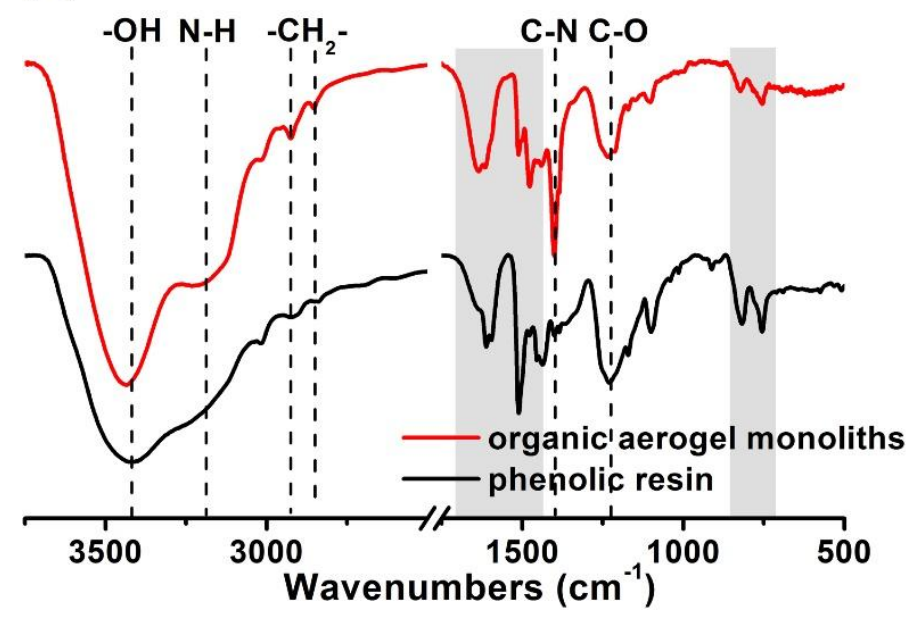

Fig. 2. Solid State ${ }^{13} \mathrm{C}-\mathrm{NMR}$ spectra (a) and FTIR spectra (b) of the phenolic resin and organic aerogel monoliths.

The sol-gel polymerization of linear phenolic resin and HMTA is very similar to the conventional curing process of novolac resin [31]. What a different is that our sol-gel synthesis is carried out in a homogenous ethanol phase and at a relatively low temperature of $80{ }^{\circ} \mathrm{C}$. During the sol-gel process, HMTA can be slowly decomposed into aldehyde and ammonia. Here the former should act as a cross-linking reagent, while the latter can serve as a base catalyst for promoting the polymerization of the former with linear phenolic resin. The 
successful build-up of HMTA-cured 3-D thermosetting phenolic network could be confirmed by solid-state ${ }^{13} \mathrm{C}-\mathrm{NMR}$ as shown in Fig. 2a. The resonance at $152.3 \mathrm{ppm}$ is due to the aromatic $\mathrm{C}$ with an $\mathrm{OH}$, the intensity of which can be taken as an internal reference in the system since it does not change during the reaction. The ortho- and para- substituted phenolic carbons appear at around $129.5 \mathrm{ppm}$ and the unsubstituted at $115.8 \mathrm{ppm}$. Obviously, the intensity of the former increases and the latter one decreases after the sol-gel reaction, suggesting the occurrence of methylene linkage reaction in which $\mathrm{H}$ at the ortho- and paraphenolic carbon is substituted by the $\mathrm{CH}_{2}$. The methylene linkage reaction can also be indicated by the increased resonance at around $33.7 \mathrm{ppm}$, the para/para methylene bridges (40.3 ppm), para/ortho methylene bridges (33.5 ppm), ortho/ortho methylene bridges (31.5 ppm) between phenolic rings [32]. Furthermore, a new resonance is observed at $120.3 \mathrm{ppm}$, which should be assigned to the intermediates, mainly substituted benzylamines [31].

The formation of cross-linked phenolic network could be also indicated by FTIR spectra (Fig. 2b). The bands around $1500 \mathrm{~cm}^{-1}$ in the left grayed area arise from aromatic ring stretching vibrations, are slightly different after the reaction, possibly due to the mono- or dis-substitution on the aromatic ring. The peaks at $2927 \mathrm{~cm}^{-1}$ and $2843 \mathrm{~cm}^{-1}$ resulting from $\mathrm{CH}_{2}$ stretching, are more visible after the reaction [33]. The peaks at $821 \mathrm{~cm}^{-1}$ and $757 \mathrm{~cm}^{-1}$ are attributed to hydrogen atoms in the aromatic rings of different substitutions (four or two free atom of hydrogen in aromatic ring respectively). And the significant decrease of their intensities after reaction also indicates the methylene linkage reaction occurring. Besides, the emergence of a peak of C-N chains at $1399 \mathrm{~cm}^{-1}$ should be originated from the substituted benzylamines, which is in a good agreement with the NMR results. The CHN analysis also 
indicates that a small amount of nitrogen atoms could be incorporated into organic aerogel framework (Table S2).

Table 1 Synthesis window with a wide range of the $\mathrm{P} / \mathrm{H}$ ratio and the phenolic resin concentration.

\begin{tabular}{ccccccccc}
\hline $\mathbf{P} / \mathbf{H}$ & $\mathbf{3}$ & $\mathbf{4}$ & $\mathbf{5}$ & $\mathbf{6}$ & $\mathbf{7}$ & $\mathbf{8}$ & $\mathbf{1 0}$ \\
\hline $\mathbf{0 . 0 5}$ & $\mathrm{P}^{b}$ & $\mathrm{P}$ & $\mathrm{P}$ & $\mathrm{P}$ & $0.07^{c}$ & 0.08 & $\mathrm{~S}^{d}$ \\
\hline $\mathbf{0 . 1 0}$ & $\mathrm{P}$ & $\mathrm{P}$ & 0.11 & 0.12 & 0.15 & 0.19 & $\mathrm{~S}$ \\
$\mathbf{0 . 1 5}$ & $\mathrm{P}$ & 0.17 & 0.18 & 0.20 & 0.24 & $\mathrm{~S}$ & $\mathrm{~S}$ \\
\hline $\mathbf{0 . 2 0}$ & 0.24 & 0.27 & 0.28 & 0.30 & 0.34 & $\mathrm{~S}$ & $\mathrm{~S}$ \\
\hline $\mathbf{0 . 2 5}$ & 0.28 & 0.30 & 0.33 & 0.34 & 0.36 & $\mathrm{~S}$ & $\mathrm{~S}$ \\
\hline $\mathbf{0 . 3 0}$ & 0.33 & 0.35 & 0.41 & 0.43 & 0.45 & $\mathrm{~S}$ & $\mathrm{~S}$ \\
\hline $\mathbf{0 . 4 0}$ & 0.44 & 0.47 & 0.51 & 0.55 & 0.57 & $\mathrm{~S}$ & $\mathrm{~S}$ \\
\hline $\mathbf{0 . 5 0}$ & 0.62 & 0.63 & 0.66 & 0.68 & $\mathrm{~S}$ & $\mathrm{~S}$ & $\mathrm{~S}$ \\
\hline
\end{tabular}

${ }^{\mathrm{a}}$ Phenolic resin concentration $\left(\mathrm{g} \mathrm{ml}^{-1}\right) .{ }^{\mathrm{b}}$ Precipitates obtained after the sol-gel reaction.

${ }^{\mathrm{c}}$ Density of carbon aerogel monoliths $\left(\mathrm{g} \mathrm{cm}^{-3}\right) .{ }^{\mathrm{d}}$ Structural collapse during the ambient pressure drying.

The sol-gel process depends on the nucleation and growth of colloidal polymer clusters, and the size of clusters will determine whether a gel remains an unbroken monolith, or seriously collapsed structure during the ambient pressure drying [34]. While the size is too small, the gel network will be collapsed during the ambient pressure drying. If the size is too 
large, grain precipitation occurs instead of the formation of gel. Thus, control of cluster size is of virtual important for the ambient-drying preparation of OAMs. Several factors, including the type of phenolic resin, the mass ratio of phenolic resin to HMTA $(\mathrm{P} / \mathrm{H})$, the resin concentration were thus investigated. It is found that only linear phenolic resin with low Mw ( 1500 $\left.\mathrm{g} \mathrm{mol}^{-1}\right)$ could form 3D robust gel, while branched resole resin or linear phenolic resin with high $\mathrm{Mw}$ of $\sim 3000 \mathrm{~g} \mathrm{~mol}^{-1}$ results in the polymer precipitating. In cast of resin with Mw of $1500 \mathrm{~g} \mathrm{~mol}^{-1}$, the successful preparation of aerogel monoliths relies on the balance between the $\mathrm{P} / \mathrm{H}$ and the phenolic resin concentration, and the resulting synthesis window and the resultant densities of CAMs are summarized in Table 1. It is obvious that there were three different macro-appearances (flocky precipitates, aerogel monoliths and structural collapse, see Fig. S2) for organic aerogels after ambient pressure drying. Here is exemplified using a fixed phenolic resin concentration of $0.15 \mathrm{~g} \mathrm{ml}^{-1}$. As shown in Fig. S2, excessive amount of HMTA $(\mathrm{P} / \mathrm{H}<3)$ results in flocky precipitates rather than monoliths. But once the $\mathrm{P} / \mathrm{H}$ ratio reaches a certain level $(\mathrm{P} / \mathrm{H}>7)$, great shrinkage and structural collapse occur. Only at the appropriate $\mathrm{P} / \mathrm{H}$ ratio of $4-7$, the golden-yellow organic aerogel monoliths could be obtained with low linear shrinkage (below 6\%) after ambient pressure drying. Meanwhile, with the increase of resin concentration, the aerogel monoliths could be obtained only at a relatively low $\mathrm{P} / \mathrm{H}$ ratio. No precipitate is observed for resin with the concentration up to $0.25 \mathrm{~g} \mathrm{ml}^{-1}$, but the capillary stress leads to structural collapse of aerogels with high $\mathrm{P} / \mathrm{H}$ ratio. 


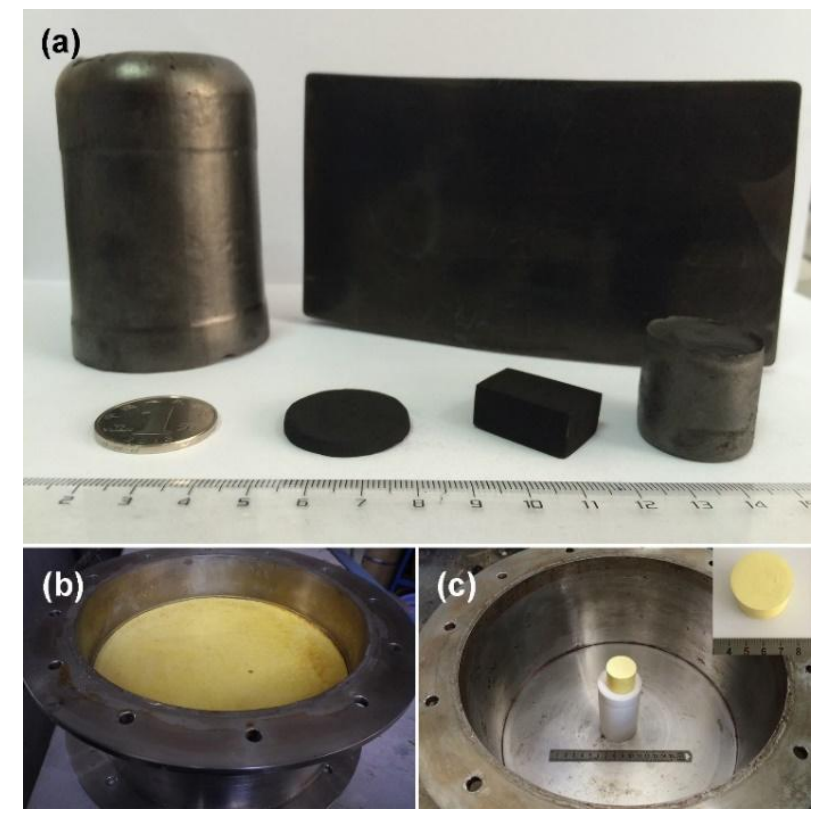

Fig. 3. Photographs of CAMs (a) and OAMs (b, c) with different sizes and shapes.

After heat treatment under inert atmosphere, the obtained CAMs are all crack-free despite of the huge shrinkage and inevitable weight loss during carbonization. The volume shrinkage and carbonization yield of the representative CAMs are in the range of 51.6-53.3\% and $54.5-56.9 \%$, respectively (Table S1). Owing to the versatility of the synthesis, a series of robust CAMs with the density ranging from $0.07-0.68 \mathrm{~g} \mathrm{~cm}^{-3}$ could be successfully prepared (see Table 1). The lowest density of CAMs could be only $0.07 \mathrm{~g} \mathrm{~cm}^{-3}$, which is much lower than previous reports, even for those obtained by supercritical drying $[35,36]$. The shape of the monolithic body can be chosen more or less at will, since it is determined by the shape of the vessel in which the synthesis is carried out (Fig. 3a). In addition, it is easy to directly scale up the preparation of OAMs just by using a larger vessel. For example, a crack-free OAM with large size of $\varphi 30 \times 10 \mathrm{~cm}$ (Fig. 3b) was made with a $5 \mathrm{~L}$ mold, which has almost the same microstructure with its small-size $(\varphi 3 \times 4 \mathrm{~cm}$, Fig. 3c) counterpart (Fig. S3). More importantly, it can be easily post-processed CAMs into monolithic sheets by 
wire-electrode cutting (also see Fig. 3a), due to their mechanically robust and conductive properties. Such machinable characteristic will allow these CAMs suitable for many potential applications.

\subsection{Porous structures of CAMs}
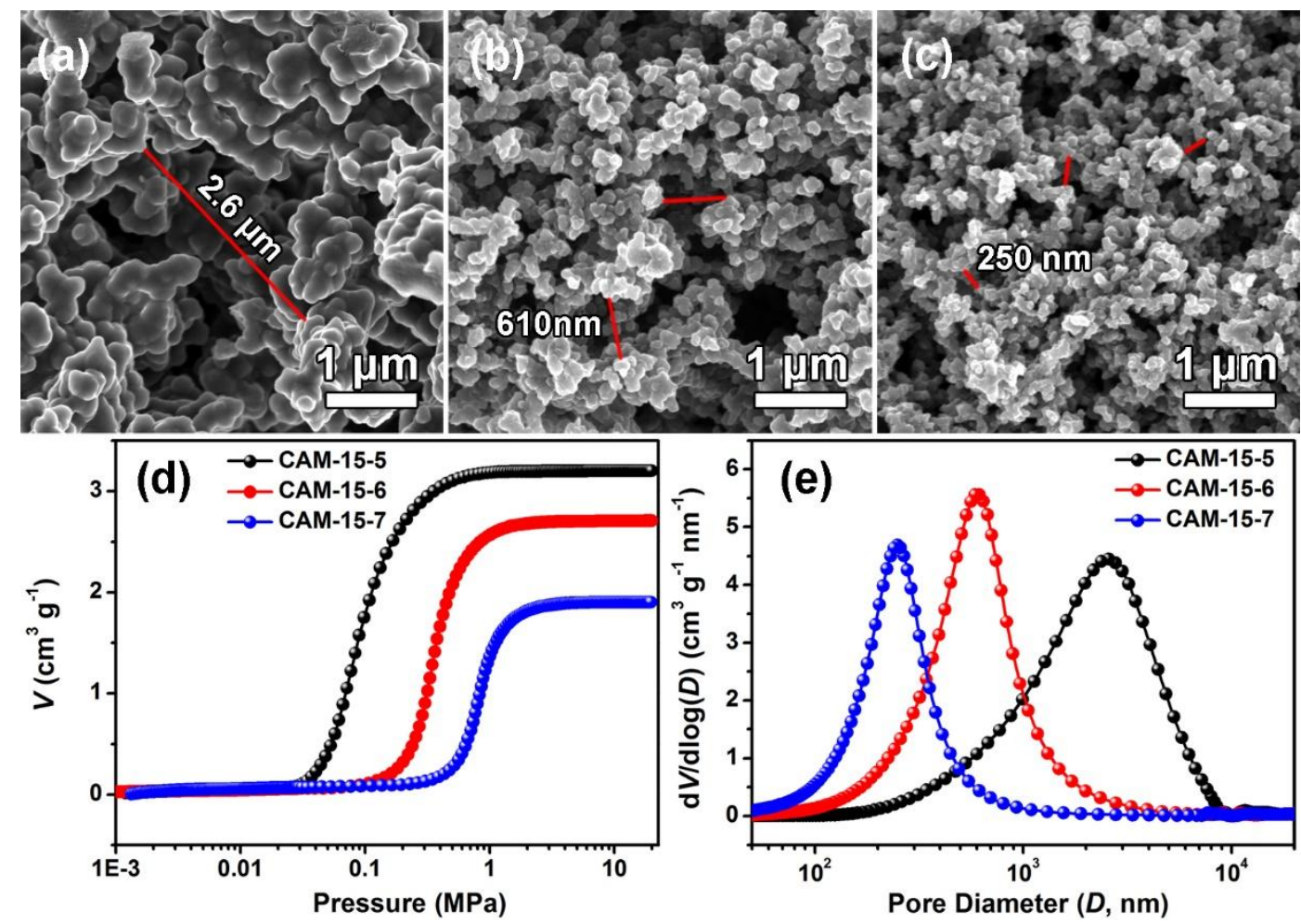

Fig. 4. SEM images of the CAM-15-y: $y=5$ (a) $y=6$ (b) $y=7$ (c), raw intrusion curves (d) and pore size distributions (e) of the CAM-15-y detected by mercury porosimetry.

The particle size and particle-overlapped macrostructure of CAMs could be easily adjusted by changing the $\mathrm{P} / \mathrm{H}$ ratio or the phenolic resin concentration. Here we exemplify two series of samples. Fig. 4a-c show the SEM images of CAMs prepared at different ratios of $\mathrm{P} / \mathrm{H}$ with a fixed resin concentration of $0.15 \mathrm{~g} \mathrm{ml}^{-1}$. These CAMs show typically 3D porous network formed by the inter-linking of irregular particles. Interestingly, the average diameter 
of carbon nanoparticles decreases gradually from $300 \mathrm{~nm}$ to $100 \mathrm{~nm}$, while the $\mathrm{P} / \mathrm{H}$ ratio increases from 5 to 7. Accordingly, the network becomes more compact for CAMs. It should be noted that, in the traditional RF system, the particle size of RF aerogel increases with the decrease of catalyst concentration. But in our case, the HMTA plays dual roles on the reaction. On one hand, it affords basic amine catalyst for accelerating the methylene-linkage cross-linking reaction. More importantly, it serves as the cross-linking agent directly involves in the reaction. With the increased amount of HMTA, more cross-linking reaction will occur to form the polymer clusters with larger particle size, thus giving CAMs with larger macroporous structure.

In addition, it is remarkable that macropores (> 50 nm) are easily observed among these carbon particles (Fig. 4a-c). These macropores are attributed to the interval gaps between chains of interconnected particles, which could be measured by the mercury porosimetry method (Fig. 4d, e). Curves of these samples are almost identical: as pressure increases, the samples first get denser and then intrusion abruptly occurs. These curves suggest the CAMs have high compressive strengths and they do not undergo densification or pores hierarchical collapse when submitted to mercury porosimetry. By using Washburn equation [37], the pore size at the maximum of each distribution (Fig. 4e) could be determined, which decreases from $2600 \mathrm{~nm}$ to $250 \mathrm{~nm}$ as $\mathrm{P} / \mathrm{H}$ ratio increases, in consistent with the results observed from SEM images (Fig. 4a-c). In addition, the macropore volume of CAMs could adjust in the range of $1.89-3.20 \mathrm{~cm}^{3} \mathrm{~g}^{-1}$. The detailed pore structure of CAMs is listed in Table 2. These abundant macropores should be one of preconditions for successful ambient pressure drying, which could reduce the capillary pressure to prevent collapse and shrinkage of gels. 


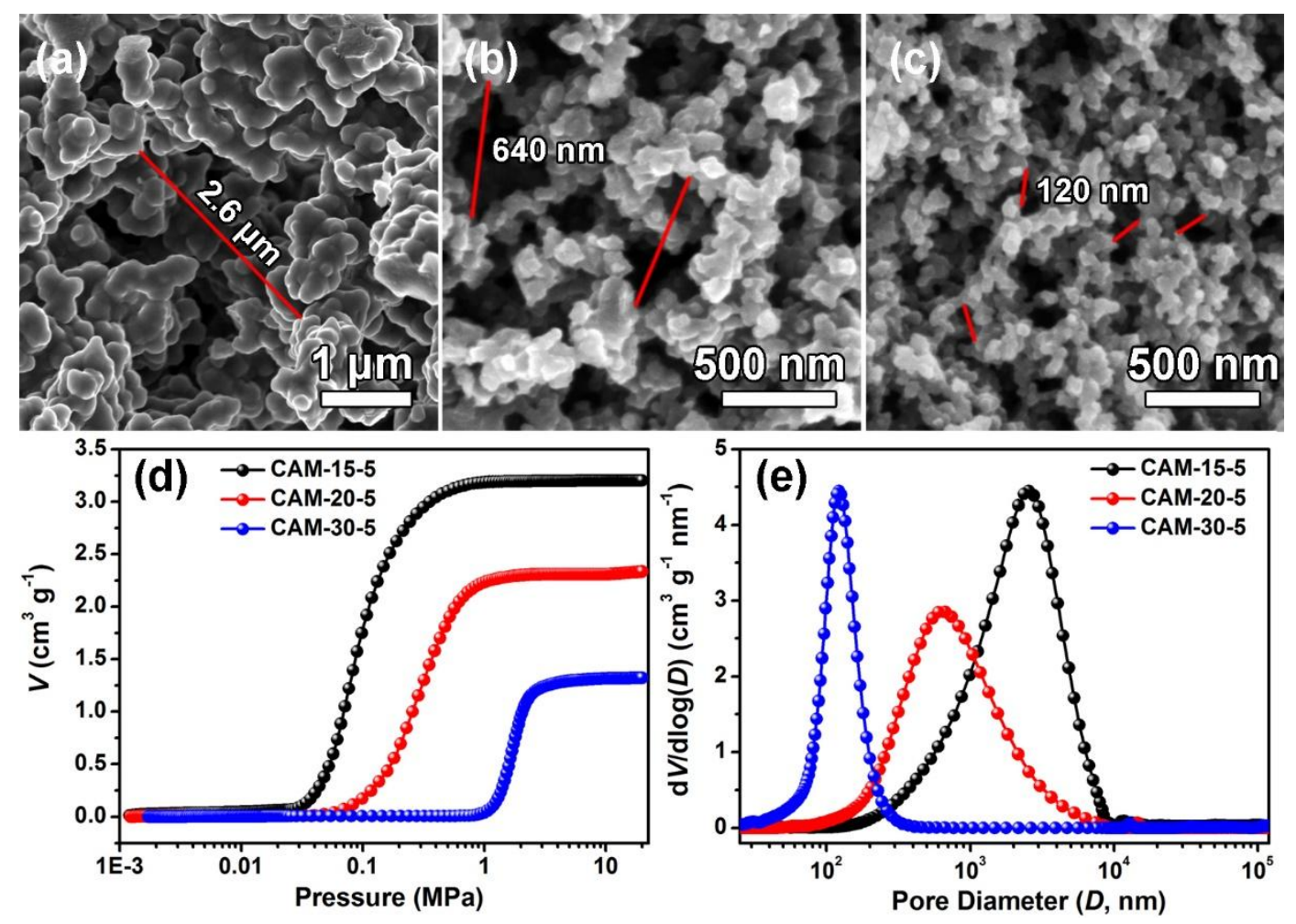

Fig. 5. SEM images of the CAM- $x-5: x=15$ (a) $x=20$ (b) $x=30$ (c), raw intrusion curves (d) and pore size distributions (e) of the CAM-X-5 detected by mercury porosimetry.

The phenolic resin concentration is also crucial for the final porous structure of the CAMs. Fig. 5a-c show the SEM images of CAMs prepared at different resin concentrations with a fixed $\mathrm{P} / \mathrm{H}$ ratio of 5 . Obviously, the CAMs obtained at higher resin concentration exhibit finer structure with smaller particles. This phenomenon is same to traditional RF system, in which the particle size decreases with the increase of the solid concentration [3]. The macroporous structure of these CAMs are also characterized by mercury porosimetry, as shown in Fig. 5d, e. It is noted that the pore volume decreases from $3.20 \mathrm{~cm}^{3} \mathrm{~g}^{-1}$ to $1.23 \mathrm{~cm}^{3}$ $\mathrm{g}^{-1}$ as the resin concentration increases, due to the high nanoparticle packing content. The pore sizes at the maximum of each distribution (Fig.5e) are calculated to be $2600 \mathrm{~nm}, 640 \mathrm{~nm}$, $120 \mathrm{~nm}$, respectively, all of which are in the macroporous range. 
Table 2 Porosity parameters of the CAMs.

\begin{tabular}{cccccccc}
\hline & \multicolumn{3}{c}{ Nitrogen adsorption/desorption } & \multicolumn{3}{c}{ Mercury porosimetry } \\
\cline { 2 - 7 } Samples & $S_{\mathrm{BET}}{ }^{\mathrm{a}}$ & $S_{\text {mic }}{ }^{\mathrm{b}}$ & $V_{\text {total }}{ }^{\mathrm{c}}$ & $V_{\text {mic }}{ }^{\mathrm{d}}$ & & $V_{\text {mac }}{ }^{\mathrm{e}}$ & $D_{\text {mac }}^{\mathrm{f}}$ \\
& $\mathrm{m}^{2} \mathrm{~g}^{-1}$ & $\mathrm{~m}^{2} \mathrm{~g}^{-1}$ & $\mathrm{~cm}^{3} \mathrm{~g}^{-1}$ & $\mathrm{~cm}^{3} \mathrm{~g}^{-1}$ & & $\mathrm{~cm}^{3} \mathrm{~g}^{-1}$ & $\mathrm{~nm}$ \\
\hline CAM-15-5 & 857 & 751 & 0.53 & 0.29 & $/$ & 3.20 & 2600 \\
CAM-15-6 & 733 & 647 & 0.47 & 0.25 & $/$ & 2.71 & 610 \\
CAM-15-7 & 574 & 507 & 0.41 & 0.20 & $/$ & 1.89 & 250 \\
CAM-20-5 & 577 & 481 & 0.40 & 0.19 & $/$ & 2.33 & 640 \\
CAM-30-5 & 487 & 405 & 0.36 & 0.17 & $/$ & 1.23 & 120 \\
\hline
\end{tabular}

${ }^{a}$ BET specific surface area. ${ }^{\mathrm{b}}$ Micropore $(<2 \mathrm{~nm})$ surface area calculated by DFT method. ${ }^{\mathrm{c}}$ Total pore volume at $P / P_{0}=0.995 .{ }^{\mathrm{d}}$ Micropore $(<2 \mathrm{~nm})$ volume calculated by DFT method. ${ }^{\mathrm{e}}$ Macropore pore volume (> $50 \mathrm{~nm}$ ) determined by mercury porosimetry. ${ }^{\mathrm{f}}$ Pore size at the maximum of the distribution determined by mercury porosimetry.

Normally, micropores could be created by the decomposition and release of small organic molecules during the carbonization. Fig. 6 a, c shows the $\mathrm{N}_{2}$ adsorption-desorption isotherms of the CAMs. All isotherms exhibit a sharp increment at low relative pressure, which indicates the presence of considerable micropores. At a relative pressure close to unity, the adsorption amount rapidly increase, which essentially reveals that plenty of macropores are present. These samples show no obvious hysteresis loops (responding to mesoporosity), as compared with those RF based carbon aerogels obtained by supercritical drying [2, 38]. 
The pore size distributions (PSDs) calculated using the DFT model (Fig. 6b, d) show the CAMs have relatively narrow microporous size distribution centered at $0.6-0.7 \mathrm{~nm}$. These micropores in the monolithic structure should held the advantages of shape-selectivity/size-selectivity for guest molecules and supply high adsorption capacity, while the presence of macropores could act as a transport system for liquids and gases [39, 40]. The detailed porosity parameters are summarized in Table 2 . The highest specific surface area $\left(S_{\mathrm{BET}}\right)$ and total pore volume $\left(V_{\text {total }}\right)$ are $857 \mathrm{~m}^{2} \mathrm{~g}^{-1}$ and $0.53 \mathrm{~cm}^{3} \mathrm{~g}^{-1}$, respectively, which are mostly contributed by the micropores.
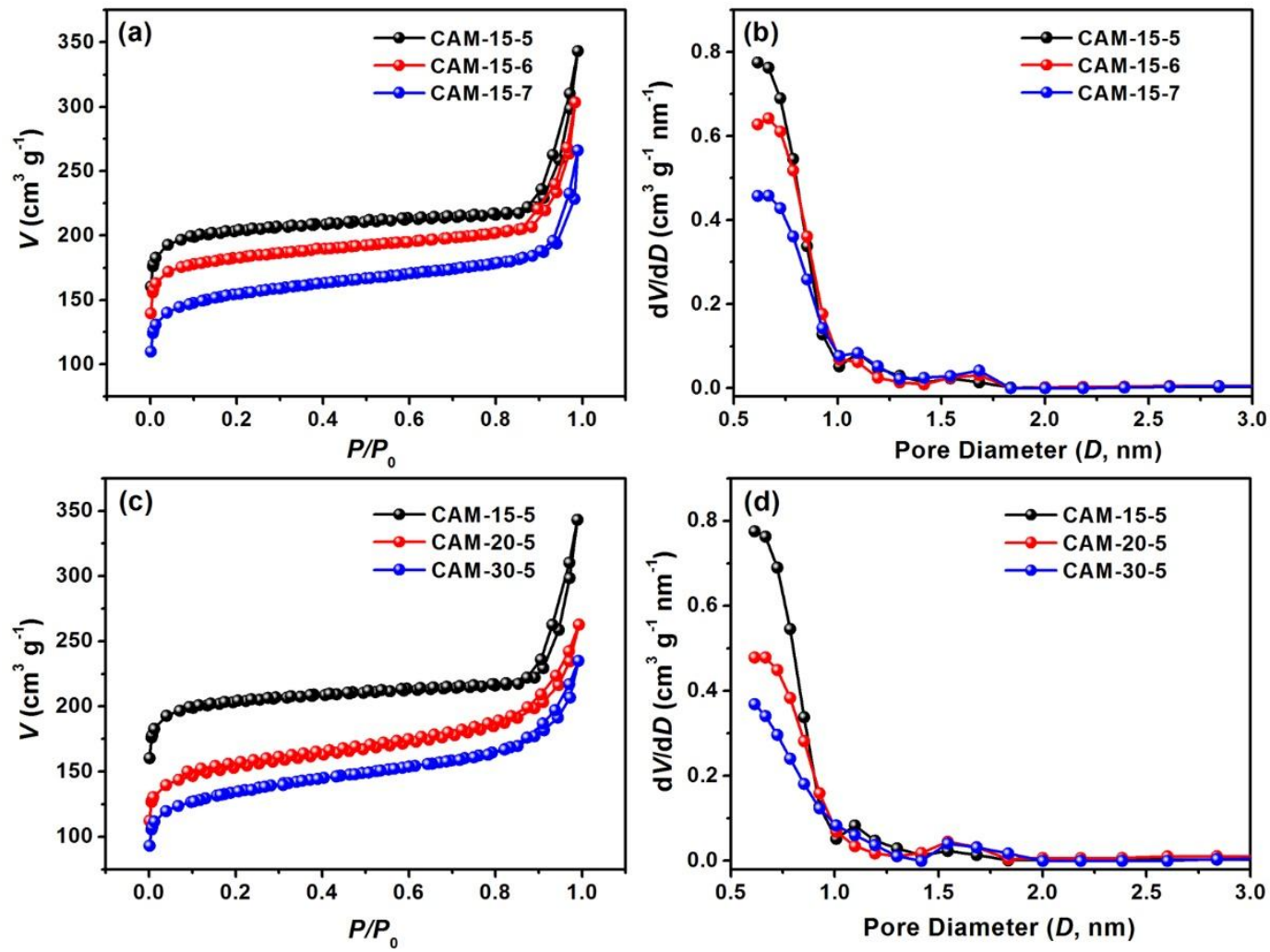

Fig. 6. $\mathrm{N}_{2}$ adsorption-desorption isotherms $(\mathrm{a}, \mathrm{c})$ and DFT pore size distributions $(\mathrm{b}, \mathrm{d})$ of the CAM-15-y (a, b) and CAM-x-5 (c, d). 

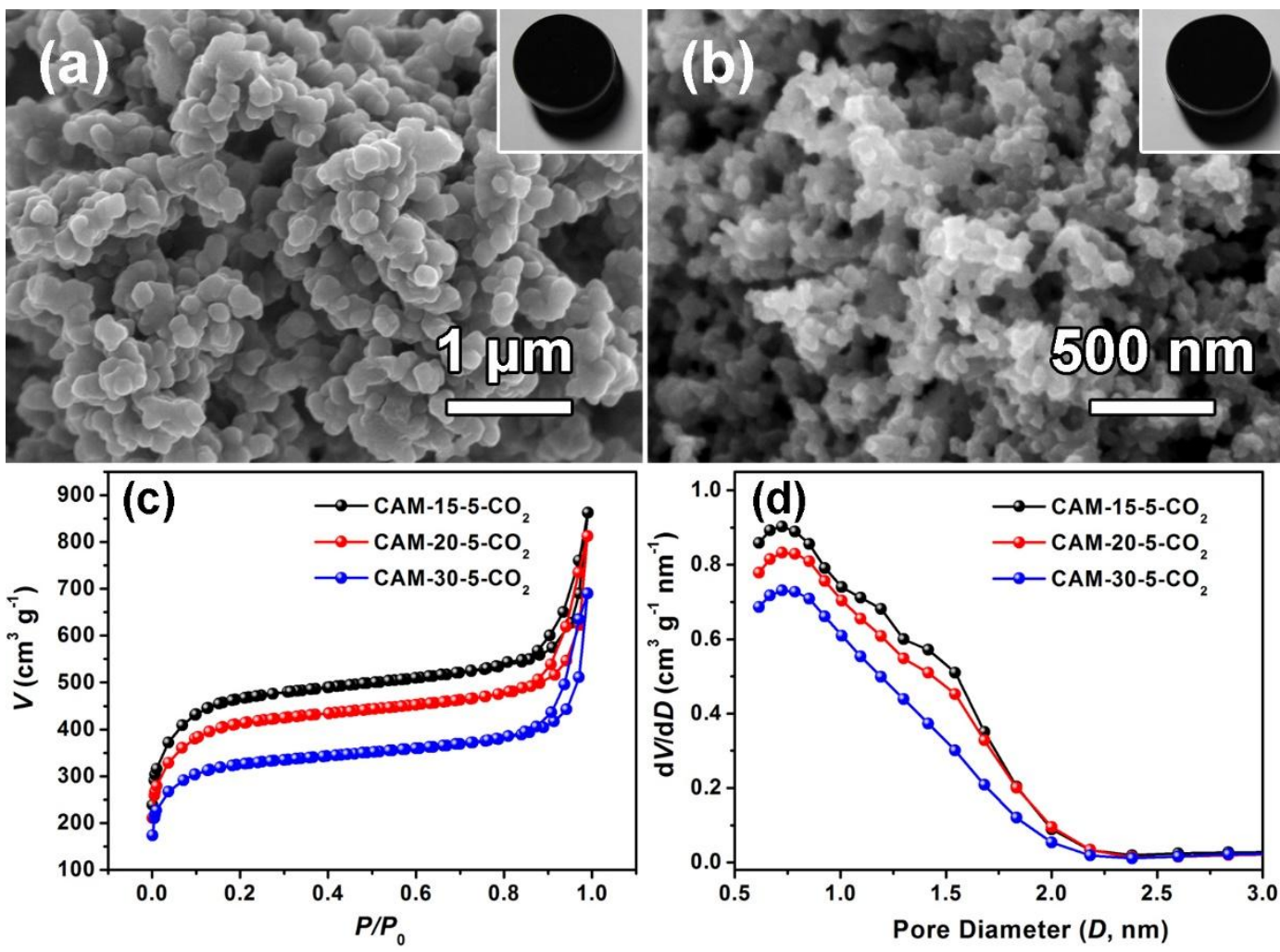

Fig. 7. SEM images of the CAM-15-5-CO $(\mathrm{a})$ and $\mathrm{CAM}-30-5-\mathrm{CO}_{2}$ (b) with the photographs in the right corner, $\mathrm{N}_{2}$ adsorption-desorption isotherms (c) and DFT pore size distributions (d) of the CAM-x-5- $\mathrm{CO}_{2}$.

It should be noted the microporosity within the individual carbon particle could be further improved by $\mathrm{CO}_{2}$ activation. Due to the presence of abundant macropores and robust skeleton, the $\mathrm{CO}_{2}$ could easily get access to the inner pore channels without causing collapse of the network (see Fig.7a, b). Thus monolithic structures could be perfectly maintained despite of the decreasing carbon particles as seen in Fig.7 a-b. The $\mathrm{N}_{2}$ adsorption-desorption isotherms and the resulting DFT pore size distributions of the $\mathrm{CO}_{2}$ activated samples are shown in Fig. $7 \mathrm{c}$, d. With the same activation conditions, the CAMs with lower concentrations have obviously higher porosity, the same trend as the un-activated samples. 
$\mathrm{CO}_{2}$ activated samples have pore size predominantly ranging from $0.6-2 \mathrm{~nm}$, significantly wider than the un-activated samples. The specific surface area and pore structure parameters are listed in Table S2. The highest BET surface area and total pore volume of the activated samples could be achieved to $1801 \mathrm{~m}^{2} \mathrm{~g}^{-1}$ and $1.30 \mathrm{~cm}^{3} \mathrm{~g}^{-1}$, respectively, which are much higher than these of the non-activated counterpart. Apparently, these activated CAMs with higher surface area is favour for various adsorption and electrochemical applications where micropore plays a dominate role.

\subsection{Mechanical and thermal insulation properties of CAMs}
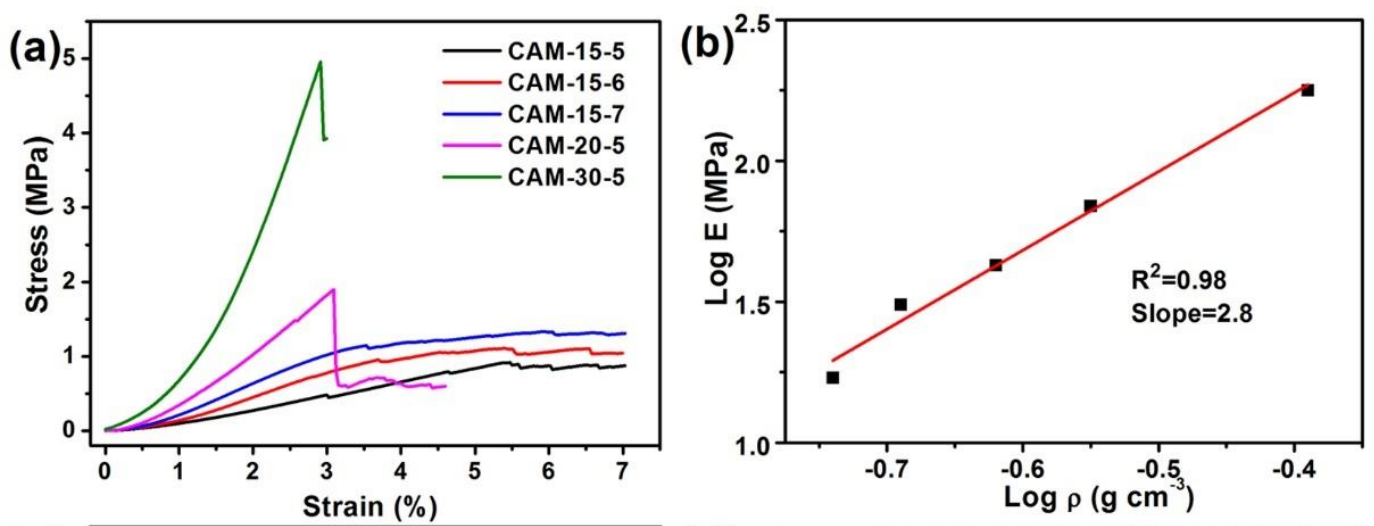

(c)

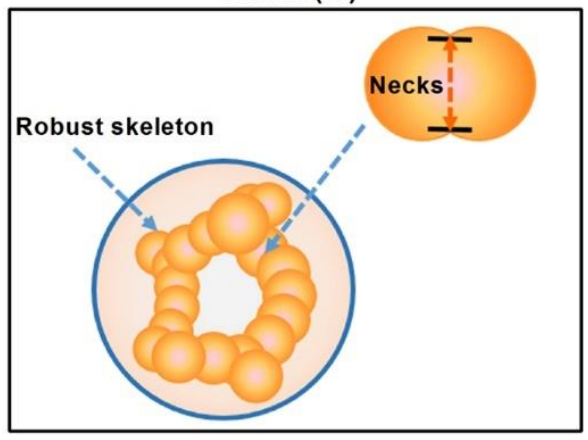

(d)

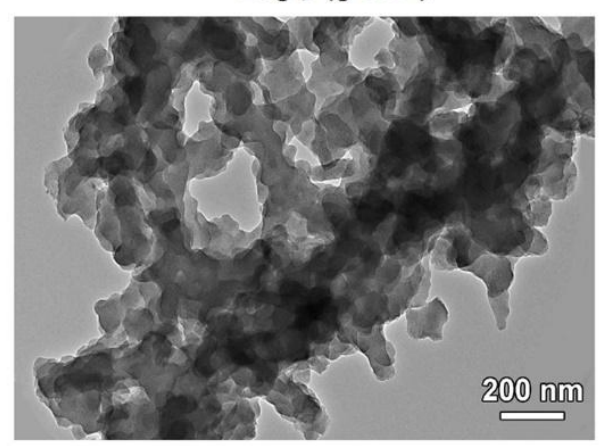

Fig. 8. Compressive strain-stress curves (a), the relationship between the Young's modulus $E$ and density $\rho$ (b), schematic illustration of the necks (c) and TEM image (d) of the representative CAMs. 
Mechanical strength is one of the essential requirements of aerogels because compressive forces are often encountered during various applications [6, 41]. The uniaxial compression tests were used to characterize the mechanical properties using cylindrical CAMs samples (ca. $\varphi 3 \times 5 \mathrm{~cm}$ ). The compressive stress-strain responses are plotted in Fig. 8a. At relatively low densities of $0.18-0.24 \mathrm{~g} \mathrm{~cm}^{-3}$, the properties of CAMs seem to transition from brittle to ductile, because they have a long linear elastic range followed by a plateau of almost constant average stress level which is interrupted by small cracks. Above densities of $0.28 \mathrm{~g} \mathrm{~cm}^{-3}$, CAMs fail abruptly at strains $<3 \%$, responding to highly brittle fracture. The reason for the increased compressibility of CAMs at low densities may be attributed to the increased porosity which allow them to bend rather than fracture in response to compressive loads. The elastic moduli $E$ of all the CAMs are extracted from the stress-strain curves, where the logarithm of the $E$ is linear with the logarithm of the density $\rho$ (Fig. 8b). The calculated slope of 2.8 is in good agreement with the reported values for the silica or organic aerogels (2.2-3.7) [42, 43].

Table 3 Mechanical properties of representative CAMs

\begin{tabular}{cccc}
\hline Samples & Density $\left(\mathrm{g} \mathrm{cm}^{-3}\right)$ & $E^{\mathrm{a}}(\mathrm{MPa})$ & $\sigma_{\max }^{\mathrm{b}}(\mathrm{MPa})$ \\
\hline CAM-15-5 & 0.18 & 17.0 & 0.9 \\
CAM-15-6 & 0.20 & 30.9 & 1.1 \\
CAM-15-7 & 0.24 & 42.7 & 1.3 \\
CAM-20-5 & 0.28 & 69.2 & 1.9 \\
CAM-30-5 & 0.41 & 177.8 & 5.0 \\
\hline
\end{tabular}

${ }^{\mathrm{a}}$ Young's modulus ${ }^{\mathrm{b}}$ Maximum compressive strength 
It should be noted that rare studies on the mechanical properties were reported for low-density carbon aerogels, especially for these obtained by ambient pressure drying. Here CAMs with low densities of $0.18-0.41 \mathrm{~g} \mathrm{~cm}^{-3}$ could deliver very impressive compressive strength of 0.9-5.0 MPa (Table 3), which is higher than that of pristine RF-based carbon aerogels with similar density (3.7 $\mathrm{MPa}$ at a density of $0.42 \mathrm{~g} \mathrm{~cm}^{-3}$ ) [28]. Such high mechanical properties should be ultimately traced to their structure. Microscopically, similar to conventional carbon aerogels, CAMs also consist of a "pearl-necklace"-like fractal network of secondary carbon nanoparticles. The fragility of the aerogel framework is traced to the inter-particle connecting zones, referred to as necks. Consequently, it seems reasonable that when the inter-particle necks are rendered thicker, the specific stiffness and strength of the aerogels could be improved without incurring a severe weight penalty. Necks are formed by coagulation of polymer particles upon slow gelation and grow to a certain point by dissolution and re-precipitation of polymer clusters during aging process (Fig. 8c). In our synthesis, the sol-gel polymerization of linear phenolic resin with HMTA in ethanol allows the slow growth of very large polymer clusters and compact particle connectivity (see TEM image in Fig. 8d). Thus, it is shown that the resulting CAMs could simultaneously combine two conflicting features-mechanically strong and low density for the first time. 


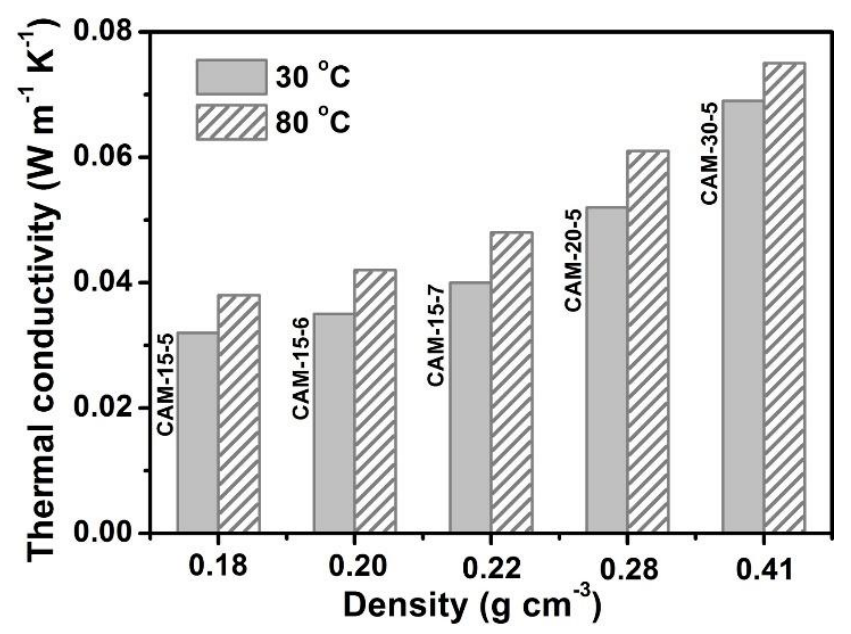

Fig. 9. The thermal conductivities of the CAMs.

Generally, carbon aerogels are predicted to have higher thermal conductivities because of the higher solid conductivity of the carbon matrix as compared with silica, but they are very promising for high temperature thermal insulation in a vacuum or inert atmosphere [44]. Here the thermal conductivities of the CAMs at room temperature $\left(30^{\circ} \mathrm{C}\right)$ and $80{ }^{\circ} \mathrm{C}$ were determined with the periodic heat flux method. The results for the thermal conductivities $\lambda$ are shown in Fig. 9, which shows that the thermal properties are principally governed by the CAM density, rather than the pore size. The heat transport through a porous solid consists of a radiative, a gaseous and a solid contribution [45]. At room temperature, the radiative and gaseous thermal conductivities could be negligible, thus the density-dependent solid conductivity contribute to the total $\lambda$. The lowest $\lambda$ at room temperature $\left(30^{\circ} \mathrm{C}\right)$ is $0.032 \mathrm{~W}$ $\mathrm{m}^{-1} \mathrm{~K}^{-1}$ obtained for CAM-15-5 with a density of $0.18 \mathrm{~g} \mathrm{~cm}^{-3}$, while for CAM-30-5 with a density of $0.41 \mathrm{~g} \mathrm{~cm}^{-3}$, the $\lambda$ is increased to $0.069 \mathrm{~W} \mathrm{~m}^{-1} \mathrm{~K}^{-1}$. These values are much lower than these for established high-temperature thermal insulation materials like carbon fibers or carbon foams currently available. Typically they have densities larger than $0.2 \mathrm{~g} \mathrm{~cm}^{-3}$, high thermal conductivities of about $0.1 \mathrm{~W} \mathrm{~m}^{-1} \mathrm{~K}^{-1}$ at room temperature and comparable 
mechanical strengths of 2.5-10.0 MPa [46-48]. Thus, these outstanding merits of CAMs, including low cost, low density, low thermal conductivity, high mechanical strength and machinable features should make them promising candidates for extreme high-temperature thermal insulations for advanced industrial devices and aerospace applications.

\section{Conclusions}

In summary, we have developed a very simple and low cost method to prepare lightweight and mechanically strong carbon aerogel monoliths via an ambient pressure drying. This appears to be the first report on carbon aerogels addressing successfully all three factors that have prevented this class of materials from having a broader practical impact: low density, high mechanical strength and ambient pressure drying. The sol-gel polymerization of linear phenolic resin with HMTA leads to not only a rigid polymer chain in molecular level but also a robust framework in macroscopic level, thus withdrawing high capillary pressure to maintain pore structure under ambient conditions. The synthesis is scalable and flexible, permitting a facile control of density, porous structure and mechanical strength. In addition, these CAMs can be further treated by $\mathrm{CO}_{2}$ activation to greatly improve their microporosity without sacrificing their monolithic structure. The as-prepared CAMs have low density as low as $0.07 \mathrm{~g} \mathrm{~cm}^{-3}$, high mechanical strength of 0.9-5.0 MPa and low thermal conductivity (0.032-0.069 $\left.\mathrm{W} \mathrm{m}^{-1} \mathrm{~K}^{-1}\right)$, which can be fabricated in large sizes, as well as being post-machine into many shapes and sizes for various real-world applications.

\section{Acknowledgments}

This work was partly supported by MOST (2014CB239702) and National Science 
Foundation of China (No. 21576090, No. 51302083, No. 51172071), and Fundamental Research Funds for the Central Universities and Shanghai Rising Star Program (15QA1401300).

\section{Reference}

[1] Pekala RW, Farmer JC, Alviso CT, Tran TD, Mayer ST, Miller JM, et al. Carbon aerogels for electrochemical applications. J Non-Cryst Solids 1998; 225:74-80.

[2] Tamon H, Ishizaka H, Araki T, Okazaki M. Control of mesoporous structure of organic and carbon aerogels. Carbon 1998; 36(9): 1257-62.

[3] Al-Muhtaseb SA, Ritter JA. Preparation and properties of resorcinol-formaldehyde organic and carbon gels. Adv Mater 2003; 15(2): 101-14.

[4] Moreno-Castilla C, Maldonado-Hódar FJ. Carbon aerogels for catalysis applications: an overview. Carbon 2005; 43(3): 455-65.

[5] Biener J, Stadermann M, Suss M, Worsley MA, Biener MM, Rose KA, et al. Advanced carbon aerogels for energy applications. Energy Enviro Sci 2011; 4(3): 656-67.

[6] Hrubesh LW. Aerogel applications. J Non-Cryst Solids 1998; 225: 335-42.

[7] Lu XP, Nilsson O, Fricke J, Pekala RW. Thermal and electrical conductivity of monolithic 
carbon aerogels. J Appl Phys 1993; 73(2): 581.

[8] Smirnova A, Dong X, Hara H, Vasiliev A, Sammes N. Novel carbon aerogel-supported catalysts for PEM fuel cell application. Int J Hydrogen Energ 2005; 30(2): 149-58.

[9] Long DH, Chen QJ, Qiao WM, Zhan L, Liang XY, Ling LC. Three-dimensional mesoporous carbon aerogels: ideal catalyst supports for enhanced $\mathrm{H}_{2} \mathrm{~S}$ oxidation. Chem Commun 2009; (26): 3898-900.

[10] Meena AK, Mishra GK, Rai PK, Rajagopal C, Nagar PN. Removal of heavy metal ions from aqueous solutions using carbon aerogel as an adsorbent. J Hazard Mater 2005; 122(1-2): 161-70.

[11] Long DH, Zhang R, Qiao WM, Zhang L, Liang XY, Ling LC. Biomolecular adsorption behavior on spherical carbon aerogels with various mesopore sizes. J Colloid Interf Sci 2009; 331(1): 40-6.

[12] Li WC, Reichenauer G, Fricke J. Carbon aerogels derived from cresol-resorcinol-formaldehyde for supercapacitors. Carbon 2002; 40(15): 2955-9.

[13] Li J, Wang XY, Huang QH, Gamboa S, Sebastian PJ. Studies on preparation and performances of carbon aerogel electrodes for the application of supercapacitor. J Power Sources 2006; 158(1): 784-8.

[14] Pekala RW, Kong FM. Resorcinol-formaldehyde aerogels and their carbonized derivatives. Polym Prep 1989; 30: 221-3.

[15] Pekala RW. Low density, resorcinol-formaldehyde aerogels. US Patent 4997804, 1991.

[16] Tamon H, Ishizaka H, Mikami M, Okazaki M. Porous structure of organic and carbon aerogels synthesized by sol-gel polycondensation of resorcinol with formaldehyde. 
Carbon 1997; 35(6): 791-6.

[17] Wu DC, Fu RW, Zhang ST, Dresselhaus MS, Dresselhaus G. Preparation of low-density carbon aerogels by ambient pressure drying. Carbon 2004; 42(10): 2033-9.

[18] Zhu YD, Hu HQ, Li WC, Zhao HX. Preparation of cresol-formaldehyde carbon aerogels via drying aquagel at ambient pressure. J Non-Cryst Solids 2006; 352(30-31): 3358-62.

[19] Wu DC, Fu RW. Requirements of organic gels for a successful ambient pressure drying preparation of carbon aerogels. J Porous Mat. 2007; 15(1): 29-34.

[20] Fischer U, Saliger R, Bock V, Petricevic R, Fricke J. Carbon aerogels as electrode material in supercapacitors. J Porous Mat 1997; 4(4): 281-5.

[21] Wu DC, Fu RW, Dresselhaus MS, Dresselhaus G. Fabrication and nano-structure control of carbon aerogels via a microemulsion-templated sol-gel polymerization method Carbon. 2006; 44(4): 675-81.

[22] Reuß M, Ratke L. Subcritically dried RF-aerogels catalysed by hydrochloric acid. J Sol-Gel Sci Techn 2008; 47(1): 74-80.

[23] Wang J, Glora M, Petricevic R, Saliger R, Proebstle H, Fricke J. Carbon cloth reinforced carbon aerogel films derived from resorcinol formaldehyde. J Porous Mat 2001; 8(2): 159-65.

[24] Feng JZ, Zhang CR, Feng J. Carbon fiber reinforced carbon aerogel composites for thermal insulation prepared by soft reinforcement. Mater Lett 2012; 67(1): 266-8.

[25] Feng JZ, Zhang CR, Feng J, Jiang YG, Zhao N. Carbon aerogel composites prepared by ambient drying and using oxidized polyacrylonitrile fibers as reinforcements. ACS Appl Mater Interfaces 2011; 3(12): 4796-803. 
[26] Yang J, Li SK, Luo YM, Yan LL, Wang FC. Compressive properties and fracture behavior of ceramic fiber-reinforced carbon aerogel under quasi-static and dynamic loading. Carbon 2011; 49(5): 1542-9.

[27] Antonietti M, Fechler N, Fellinger T-P. Carbon aerogels and monoliths: control of porosity and nanoarchitecture via sol-gel routes. Chem Mater 2014; 26(1): 196-210.

[28] Fu RW, Zheng B, Liu J, Weiss S, Ying JY, Dresselhaus MS, et al. Fabrication of activated carbon fibers/carbon aerogels composites by gelation and supercritical drying in isopropanol. J Mater Res 2003; 18(12): 2765-73.

[29] Zhong Y, Kong Y, Shen XD, Cui S, Yi XB, Zhang JJ. Synthesis of a novel porous material comprising carbon/alumina composite aerogels monoliths with high compressive strength. Micropor Mesopor Mat. 2013; 172: 182-9.

[30] Rojas-Cervantes ML. Some strategies to lower the production cost of carbon gels. J Mater Sci 2015; 50(3): 1017-40.

[31] Zhang XQ, Looney MG, Solomon DH, Whittaker AK. The chemistry of novolac resins: 3. $13 \mathrm{C}$ and $15 \mathrm{~N}$ n.m.r. studies of curing with hexamethylenetetramine. Polymer 1997; 38(23): 5835-48.

[32] Rego R, Adriaensens PJ, Carleer RA, Gelan JM. Fully quantitative carbon-13 NMR characterization of resol phenol-formaldehyde prepolymer resins. Polymer 2004; 45(1): $33-8$.

[33] García BB, Liu DW, Sepehri S, Candelaria S, Beckham DM, Savage LW, et al. Hexamethylenetetramine multiple catalysis as a porosity and pore size modifier in carbon cryogels. J Non-Cryst Solids 2010; 356(33-34): 1620-5. 
[34] ElKhatat AM, Al-Muhtaseb SA. Advances in tailoring resorcinol-formaldehyde organic and carbon gels. Adv Mater 2011; 23(26): 2887-903.

[35] Job N, Théry A, Pirard R, Marien J, Kocon L, Rouzaud J-N, et al. Carbon aerogels, cryogels and xerogels: influence of the drying method on the textural properties of porous carbon materials. Carbon 2005; 43(12): 2481-94.

[36] Wu DC, Fu RW, Sun ZQ, Yu ZQ. Low-density organic and carbon aerogels from the sol-gel polymerization of phenol with formaldehyde. J Non-Cryst Solids 2005; 351(10-11): 915-21.

[37] Washburn EW. Note on a method of determining distribution of pore sizes in a porous material. Proc Nat Acad Sci 1921; 7(4): 115-6.

[38] Horikawa T, Hayashi Ji, Muroyama K. Controllability of pore characteristics of resorcinol-formaldehyde carbon aerogel. Carbon 2004; 42(8-9): 1625-33.

[39] Gong YT, Wei ZZ, Wang J, Zhang PF, Li HR, Wang Y. Design and fabrication of hierarchically porous carbon with a template-free method. Sci Rep 2014; 4: 6349.

[40] Hao GP, Li WC, Qian D, Wang GH, Zhang WP, Zhang T, et al. Structurally designed synthesis of mechanically stable poly(benzoxazine-co-resol)-based porous carbon monoliths and their application as high-performance $\mathrm{CO}_{2}$ capture sorbents. J Am Chem Soc 2011; 133(29): 11378-88.

[41] Maleki H, Durães L, Portugal A. An overview on silica aerogels synthesis and different mechanical reinforcing strategies. J Non-Cryst Solids 2014; 385: 55-74.

[42] Pekala RW, Alviso CT, LeMay JD. Organic aerogels: microstructural dependence of mechanical properties in compression. J Non-Cryst Solids 1990; 125(1): 67-75. 
[43] Woignier T, Reynes J, Hafidi Alaoui A, Beurroies I, Phalippou J. Different kinds of structure in aerogels: relationships with the mechanical properties. J Non-Cryst Solids 1998; 241(1): 45-52.

[44] Wiener M, Reichenauer G, Braxmeier S, Hemberger F, Ebert HP. Carbon aerogel-based high-temperature thermal insulation. Int J Thermophys 2009; 30(4): 1372-85.

[45] Lu X, Caps R, Fricke J, Alviso CT, Pekala RW. Correlation between structure and thermal conductivity of organic aerogels. J Non-Cryst Solids 1995; 188(3): 226-34.

[46] He X, Tang ZH, Zhu YF, Yang JH. Fabrication of carbon foams with low thermal conductivity using the protein foaming method. Mater Lett 2013; 94: 55-7.

[47] Chen C, Kennel EB, Stiller AH, Stansberry PG, Zondlo JW. Carbon foam derived from various precursors. Carbon, 2006; 44(8): 1535-43.

[48] Mlnus M, Kumar S. The processing, properties, and structure of carbon fibers. JOM 2005; 57(2): 52-8. 